\title{
Hubungan Motivasi Kerja Dan Dukungan Sosial Kepala Sekolah Dengan Pelaksanaan Tugas Guru BK Di SMPN Kab. Kerinci
}

Rahmawati; Neviyarni ; Firman Firman

Universitas Negeri Padang, Universitas Negeri Padang \& Universitas Negeri Padang

Email : rahma_jelo@yahoo.com

\begin{abstract}
The counselor job and responbility is to give guidance and counseling service, performing the job needs motivation in order to reach the educational purpose. The headmaster is responsible to provide the facilities for the counselor in doing them job. The purpose of the study is to find out the relationships between the headmaster's working motivation and social support with counselor performance. This research used quantitative in nature, using correlation method. Objective of the Research be done counselor in Junior high school Kerinci. The results of the study revealed that, there is a significant relationship between the headmaster's working motivation and social support with the counselor performance.
\end{abstract}

Keywords: Working Motivation, Social Support, The Counselor Performance.

Copyright $(2016$ Universitas Negeri Padang All rights reserved

\section{PENDAHULUAN}

Guru BK di sekolah mempunyai peran penting dalam meningkatkan tujuan pendidikan, Tugas guru BK memberikan pelayanan kepada peserta didik untuk mencapai tugas-tugas perkembagannya. Sebagaimana tercantum dalam PP nomor 74 tahun 2008 dijelaskan bahwa, guru mata pelajaran, dengan tugas pokok merencanakan pembelajaran, melaksanakan pembelajaran, menilai hasil pembelajaran, membimbing dan melatih peserta didik dan melaksanakan tugas tambahan. Sedangkan guru bimbingan dan konseling memiliki tugas, tanggung jawab dan wewenang dalam pelaksanaan pelayanan bimbingan dan konseling terhadap peserta didik.

Realita yang terjadi di lapangan saat ini antara lain: SMPN 16 Kerinci, SMPN 21 Kerinci, SMPN 23 Kerinci, SMPN 24 Kerinci, SMPN 26 Kerinci, SMPN 29 Kerinci, SMPN 34 Kerinci, SMPN 42 Kerinci bahwa, guru BK tidak mempunyai program sebagai panduan dalam melakukan kegiatan BK di sekolah, terkesan kegiatan BK dilakukan seadanya. Sehingga pelaksanaan tugas guru BK sulit untuk mewujudkan palayanan yang optimal.

Dewa Ketut Sukardi (2003:127) menjelaskan kewajiban dan tugas guru BK di sekolah di antaranya: (a) mensosialisasikan kegiatan layanan BK, (b) merencanakan program BK, (c) melaksanakan persiapan termasuk perencanaan kegiatan BK, (d) melaksanakan layanan BK terhadap sedikitnya 150 orang siswa, (e) melaksanakan kegiatan pendukung BK, (f) mengadakan penilaian proses dan hasil kegiatan layanan BK, (g) menganalisis hasil penilaian BK, (h) melaksanakan tindak lanjut berdasarkan hasil analisis penilaian BK, (i) mengadministrasikan kegiatan BK, (j) mempertanggung jawabkan tugas dan kegiatan BK kepada Koordinator BK.

Berdasarkan pendapat ahli di atas dapat disimpulkan bahwa, sebagai pelaksana bimbingan dan konseling di sekolah yaitu guru BK hendaknya memiliki kompetensi/kemampuan dalam melaksanakan tugasnya agar pelaksanaan kegiatan bimbingan dan konseling dapat berjalan dengan baik dan tercapai tujuan pelayanannya. Mengingat pentingnya pelaksanaan tugas guru BK, guru BK perlu meningkatkan pelayanan yang optimal. 
Motivasi dalam bekerja sangat penting karena motivasi kerja yang tinggi oleh seorang guru BK akan menimbulkan kepercayaan diri yang tinggi dalam melaksanakan pekerjaannya yang telah ditetapkan. Rendahnya motivasi kerja guru BK berpengaruh terhadap proses pelaksanaan layanan bimbingan dan konseling di sekolah.

Hasil observasi ke beberapa SMPN di Kab. Kerinci antara lain: SMPN 1 Kerinci, SMPN 2 Kerinci, SMPN 11 Kerinci, SMPN 14 Kerinci, SMPN 16 Kerinci, SMPN 17 Kerinci, SMPN 23 Kerinci bahwa, faktor yang mempengaruhi rendahnya motivasi kerja guru BK disebabkan oleh banyaknya peserta didik di sekolah yang harus mendapatkan pelayanan dari guru BK, dan di sekolah hanya memiliki satu orang guru BK dengan kondisi demikian membuat tugas guru BK menumpuk dan jenuh untuk melakukan pekerjaan, sehingga pencapaian tugas pelaksanaan BK di sekolah tidak mencapai hasil yang maksimal.

Kemudian hal lain yang menunjukkan motivasi kerja guru BK rendah ditandai dengan kurangnya kerjasama antara guru BK dan personil sekolah, sehingga BK kurang tersosialisasi dengan baik.

Hamzah B. Uno (2010:71) menjelaskan "motivasi kerja merupakan salah satu faktor yang turut menentukan kinerja seseorang". Besar atau kecilnya pengaruh motivasi pada kinerja seseorang tergantung pada seberapa banyak intensitas motivasi yang diberikan.

Dengan demikian kerja guru BK yang kurang dilandasi oleh motivasi kerja yang tinggi akan menimbulkan rendahnya kualitas pelaksanaan tugas guru BK di sekolah. Namun sebaliknya kerja yang didorong oleh motivasi yang kuat akan meningkatkan kualitas pelaksanaan tugas seorang guru BK di sekolah.

Motivasi kerja serta dukungan sosial Kepala Sekolah turut mempengaruhi hasil pelaksanaan tugas guru BK. Kepala Sekolah ikut bertanggung jawab terhadap pelaksanaan teknis bimbingan dan konseling di sekolah

Hasil pengamatan di SMPN 11 Kerinci, SMPN 16 Kerinci, SMPN 21 Kerinci, SMPN 23 Kerinci, SMPN 24 Kerinci, SMPN 26 Kerinci. Ruang kerja guru BK yang tidak mendukung, dan masih ada guru BK yang tidak mempunyai ruang khusus, sehingga guru BK berada satu ruangan dengan guru mata pelajaran yang lain. Dengan kondisi demikian ketika siswa ingin melakukan konseling asas kerahasiaan dari proses konselingnya tidak terjamin.

Berdasarkan hasil wawancara dengan guru BK SMPN Kab. Kerinci secara keseluruhan mereka tidak mendapatkan anggaran dana dari Kepala Sekolah untuk kegiatan BK di Sekolah. Sehingga menimbulkan tantangan bagi mereka untuk mewujudkan pelayanan BK yang optimal

Dukungan sosial dari Kepala Sekolah seperti fasilitas, anggaran dana untuk kegiatan BK dapat memudahkan bagi guru BK dalam menjalankan semua kegiatan yang berkaitan dengan pelayanan BK. Taylor (2003:232) menjelaskan "dukungan sosial sebagai pertukaran interpersonal dimana seseorang memberikan bantuan atau pertolongan kepada yang lain”.

Dengan demikian dapat disimpulkan dukungan sosial yang diberikan oleh Kepala Sekolah kepada guru BK membuat guru BK merasa nyaman, diperhatikan dan dibutuhkan sehingga guru BK merasa perlu untuk meningkatkan kualitas pelaksanaan tugasnya. Dukungan sosial yang diberikan oleh seseorang kepada orang lain memberikan efek positif terhadap orang yang menerima dukungan sosial tersebut, seperti yang dijelaskan oleh Baron dan Byrne (2003:235) bahwa, pentingnya dukungan sosial (Social Support) kenyamanan secara fisik dan psikologis yang diberikan oleh orang lain.

Sehubungan dengan hal itu dalam meningkatkan pelaksanaan tugas guru BK, Kepala Sekolah harus mampu membangkitkan semangat kerja guru BK, harus mampu menciptakan suasana kerja yang menyenangkan, nyaman, serta mampu mendorong guru BK untuk bekerja dengan meberikan dukungan sosial sesuai dengan kebutuhan guru BK.

\section{METODOLOGI}


Penelitian ini menggunakan pendekatan kuantitatif dengan metode korelasional. Dalam penelitian ini terdapat dua variabel yaitu variabel bebas dan variabel terikat, dimana variabel bebasnya adalah motivasi kerja ( ) dan dukungan sosial Kepala Sekolah ( ) sedangkan variabel terikat adalah pelaksanaan tugas guru BK ( ). Sasaran penelitian adalah guru BK SMPN di Kabupaten Kerinci. Data penelitian dikumpulkan dengan menggunakan angket skala model likert kemudian dianalisis dengan menggunakan statistik non parametrik Spearman rho.

\section{HASIL}

a. Pelaksanaan Tugas Guru BK (Y)

Rekapitulasi perhitungan data pelaksanaan tugas guru BK. sasaran penelitian guru BK SMPN Kab. Kerinci dan kategorinya dapat dilihat pada tabel 1 berikut:

Tabel 1. Pengkategorian Pelaksanaan Tugas Guru BK

\begin{tabular}{|c|l|c|c|}
\hline Interval & Kategori & Prekuensi & $12,5 \%$ \\
\hline$>\mathbf{1 1 6}$ & Sangat Baik (SB) & 2 & $31,25 \%$ \\
\hline $\mathbf{1 0 4 - 1 1 5}$ & Baik (B) & 5 & $18,75 \%$ \\
\hline $\mathbf{9 2}-\mathbf{1 0 3}$ & Cukup Baik (CB) & 3 & $12,5 \%$ \\
\hline $\mathbf{8 0 - 9 1}$ & Kurang Baik (KB) & 2 & $25 \%$ \\
\hline$\leq \mathbf{7 9}$ & $\begin{array}{l}\text { Sangat Kurang Baik } \\
\text { (SKB) }\end{array}$ & 4 & \\
\hline
\end{tabular}

Berdasarkan tabel 1 di atas frekuensi pencapaian pelaksanaan tugas guru BK ternyata, kualitas pelaksanaan tugas guru BK bervariasi mulai dari kualitas sangat baik, baik, cukup baik, kurang baik, dan sangat kurang baik. Kategori sangat baik adalah 2 orang dengan persentase 12,5\%, kategori baik berjumlah 5 orang dengan persentase $31,25 \%$, sedangkan 3 orang berada pada kategori cukup baik dengan persentase $18,75 \%$, untuk kategori kurang baik berjumlah 2 orang dengan persentase 12,5\% dan kategori sangat kurang baik berjumlah 4 orang dengan persentase $25 \%$.

\section{b. Motivasi Kerja $\left(\mathbf{X}_{1}\right)$}

Rekapitulasi perhitungan data motivasi kerja. Sasaran penelitian guru BK SMPN Kab. Kerinci dan kategorinya dapat dilihat pada tabel 2 berikut:

Tabel 2. Pengkategorian Motivasi Kerja

\begin{tabular}{clcc}
\hline Interval & Kategori & Frekuensi & Persentase (\%) \\
\hline$>\mathbf{6 6}$ & Sangat Tinggi (ST) & 4 & \\
& & 2 & $25,5 \%$ \\
$\mathbf{6 1 - 6 5}$ & Tinggi (T) & 4 & $12,5 \%$ \\
$\mathbf{5 6 - 6 0}$ & Sedang (S) & 5 & $25 \%$ \\
$\mathbf{5 1 - 5 5}$ & Rendah (R) & & $31,25 \%$ \\
$\leq \mathbf{5 0}$ & Sangat Rendah (SR) & 1 & $6,25 \%$ \\
\hline
\end{tabular}

Berdasarkan tabel 2 di atas frekuensi pencapaian motivasi kerja guru BK ternyata, kualitas motivasi kerja guru BK bervariasi mulai dari kualitas sangat tinggi, tinggi, sedang, rendah, dan sangat rendah. Berdasarkan tabel 2 di atas terlihat bahwa frekuensi sangat tinggi berjumlah 4 orang dengan persentase $25 \%$, kemudian pada kategori tinggi sebanyak 2 orang perolehan persentasenya 12,5\%, pada kategori sedang sebanyak 4 orang persentase $25 \%$, kategori rendah sebanyak 5 orang dengan persentase $31,25 \%$, Selain itu terdapat 1 orang pada kategori sangat rendah dengan persentase $6,25 \%$. 


\section{c. Dukungan Sosial $\left(\mathrm{X}_{2}\right)$}

Rekapitulasi perhitungan data dukungan sosial Kepala Sekolah. Sasaran penelitiaan dalah guru BK SMPN Kab. Kerinci dan kategorinya dapat dilihat pada tabel 3 berikut:

Tabel 3. Pengkategorian Dukungan Sosial Kepala Sekolah

\begin{tabular}{|c|c|c|c|}
\hline Interval & Kategori & Frekuensi & Persentase (\%) \\
\hline$>76$ & Sangat Tinggi (ST) & & \\
\hline & & 4 & $25 \%$ \\
\hline $64-75$ & Tinggi (T) & 5 & $31,25 \%$ \\
\hline $52-63$ & Sedang (S) & 6 & $37,5 \%$ \\
\hline $40-51$ & Rendah (R) & 0 & 0 \\
\hline$\leq 39$ & Sangat Rendah (SR) & & \\
\hline & & 1 & $6,25 \%$ \\
\hline
\end{tabular}

Berdasarkan tabel 3 di atas frekuensi pencapaian dukungan sosial Kepala Sekolah ternyata, kualitas dukungan sosial Kepala Sekolah bervariasi mulai dari kualitas sangat tinggi, tinggi, sedang dan sangat rendah. Berdasarkan tabel 7 diatas terlihat bahwa sebanyak 4 orang berada pada kategori sangat tinggi dengan persentase $25 \%$, kemudian kategori tinggi sebanyak 5 orang dengan persentase $31,25 \%$, setelah itu pada kategori sedang 6 orang dengan persentase 37,5\% kemudian kategori sangat rendah sebanyak 1 orang dengan persentase $6,25 \%$.

\section{Pengujian Hipotesis}

\section{a. Hipotesis pertama}

Hipotesis yang diajukan dalam penelitian yaitu "terdapat hubungan yang signifikan antara motivasi kerja guru BK dengan pelaksanaan tugas guru BK". Hasil uji hipotesis dapat dilihat pada tabel 4 berikut:

\section{Tabel 4. Hasil Analisis Korelasi Veriabel $\left(\mathrm{X}_{1}\right)$ Dengan Variabel $(\mathbf{Y})$}

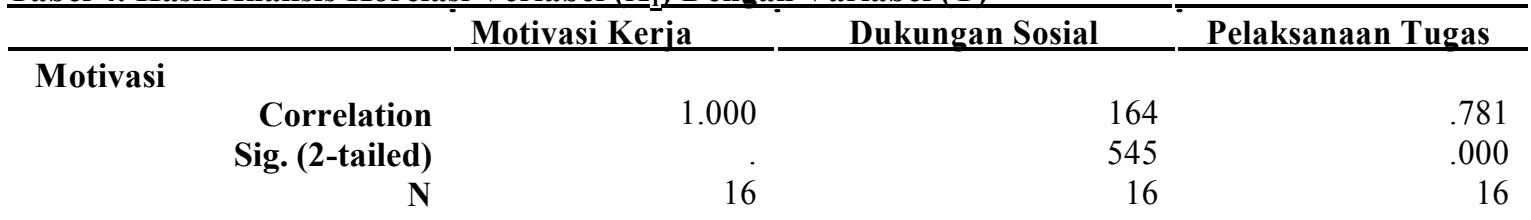

Berdasarkan tabel 4 di atas terlihat bahwa korelasi motivasi kerja guru BK dengan pelaksanaan tugas guru BK sebesar 0,781 dengan taraf signifikan 0,000 lebih kecil () dari 0,05 dengan demikian dapat disimpulan bahwa terdapat hubungan yang signifikan antara motivasi kerja $\left(\mathrm{X}_{1}\right)$ dengan pelaksanaan tugas guru BK (Y). Dengan kriteria:

- Jika taraf signifikannya 0,000 lebih kecil () 0,05 maka $\mathrm{H}_{1}$ Diterima, $\mathrm{H}_{\mathrm{o}}$ ditolak.

\section{b. Hipotesis ke dua}

Hipotesis yang diajukan dalam penelitian yaitu "terdapat hubungan yang signifikan antara dukungan sosial Kepala Sekolah dengan pelaksanaan tugas guru BK". Hasil uji hipotesis dapat dilihat pada tabel 5 berikut: 
Tabel 5. Hasil Analisis Korelasi Variabel $\left(\mathrm{X}_{2}\right)$ dengan Variabel (Y)

\begin{tabular}{lrrrr}
\hline & Motivasi Kerja & Dukungan Sosial & Pelaksanan tugas \\
\hline $\begin{array}{l}\text { Dukungan } \\
\text { Sosial }\end{array}$ & & & & \\
& Correlation & .164 & 1.000 & .145 \\
& Sig. (2-tailed) & .545 & 16 & .591 \\
& $\mathbf{N}$ & 16 & 16 & 16 \\
\hline
\end{tabular}

Berdasarkan Tabel 5 di atas, setelah dilakukan pengolahan data, maka diperoleh korelasi dukungan sosial Kepala Sekolah dengan pelaksanaan tugas guru BK sebesar 0,145 dengan taraf signifikan 0,591 lebih besar $(>)$ dari 0,05. Dengan demikain dapat disimpulkan bahwa terdapat hubungan yang tidak signifikan antara dukungan sosial Kepala Sekolah dengan pelaksanaan tugas guru BK.

Dengan kriteria:

- Jika taraf signifikannya 0,591 lebih besar () 0,05 maka $\mathrm{H}_{1}$ Ditolak, $\mathrm{H}_{\mathrm{o}}$ diterima.

\section{c. Hipotesis ke tiga}

Hipotesis yang diajukan yaitu "terdapat hubungan yang signifikan antara motivasi kerja dan dukungan sosial Kepala Sekolah secara bersama-sama dengan pelaksanaan tugas guru BK”. Hasil uji hipotesis dapat dilihat pada tabel 6 berikut:

Tabel 6. Hasil Analisis Korelasi Ganda Variabel $\left(\mathrm{X}_{1}, \mathrm{X}_{2}\right)$ dengan (Y)

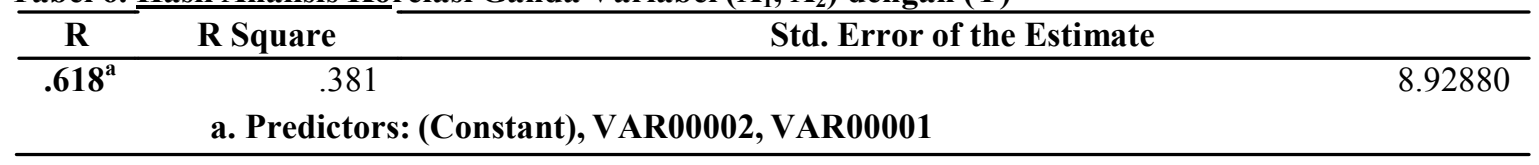

Berdasarkan tabel 6 di atas, diperoleh nilai korelasi 0,618 dengan demikian disimpulkan bahwa terdapat hubungan yang signifikan antara motivasi kerja guru BK dan dukungan sosial Kepala Sekolah secara bersama-sama dengan pelaksanaan tugas guru BK.

\section{PEMBAHASAN}

\section{a. Hubungan Motivasi Kerja Guru BK dengan Pelaksanaan Tugas Guru BK}

Temuan analisis data pelaksanaan tugas guru BK dipengaruhi oleh motivasi kerja guru BK sebesar 0,781 dengan taraf signifikan 0,000 lebih kecil () dari 0,05. Hasil demikian menunjukkan bahwa terdapat hubungan yang signifikan antara motivasi kerja dengan pelaksanaan tugas guru BK.

Motivasi dibutuhkan oleh setiap orang dalam melaksanakan suatu kegiatan atau pekerjaannya karena motivasi adalah kondisi yang dapat mengerakkan guru agar mampu mencapai tujuan dari motifnya. Jadi, jelas bahwa seorang guru BK harus memiliki motivasi yang tinggi agar dapat mencapai tujuan dari motifnya dengan mudah. Dengan demikian dapat disimpulkan pelaksanaan tugas guru BK di sekolah dipengaruhi oleh motivasi kerja guru BK.

Hasibuan (2009:141) menjelaskan motivasi kerja guru dapat menyebabkan, menyalurkan dan mendukung perilaku seorang guru agar mau bekerja giat dan antusias untuk mencapai hasil yang optimal.

\section{b. Hubungan Dukungan Sosial Kepala Sekolah dengan Pelaksanaan Tugas Guru BK}

Temuan analisis data pelaksanaan tugas guru BK dipengaruhi oleh dukungan sosial sebesar 0,145 dengan taraf signifikan 0,591 lebih besar $(>)$ dari 0,05. Hasil demikian menunjukkan bahwa terdapat hubungan yang tidak signifikan antara dukungan sosial Kepala Sekolah dengan pelaksanaan tugas guru 
Hasil temuan menjelaskan bahwa, tanpa adanya dukungan sosial dari Kepala Sekolah guru BK cenderung mengalami kesulitan dalam melaksanakan tugas. Dukungan sosial yang diberikan sangat besar pengaruhnya terhadap kehidupan orang yang menerimanya, seperti yang dijelaskan oleh Broman dalam (Taylor 2003:555) dukungan sosial bisa efektif dalam mengatasi tekanan psikologis pada masa-masa sulit dan menekan.

Dengan demikian untuk mendapatkan dukungan sosial dari Kepala Sekolah, guru BK hendaknya menunjukkan eksistensinya di sekolah. Mampu merencanakan program baik itu tahunan, semesteran, bulanan, mingguan maupun dalam bentuk RPLBK. Dengan menyesuaikan antara program yang direncanakan dengan kebutuhan siswa dan kondisi sekolah dimulai dari perencanaan, pelaksanaan, penilaian hingga tindak lanjut dari pelaksanaan BK di sekolah.

\section{c. Hubungan Motivasi Kerja dan Dukungan Sosial Kepala Sekolah secara Bersama-sama dengan Pelaksanaan Tugas Guru BK.}

Temuan analisis data motivasi kerja dan dukungan sosial Kepala Sekolah secara bersama-sama dengan pelaksanaan tugas guru BK. Menjelaskan bahwa terdapat hubungan yang signifikan antara motivasi kerja dan dukungan sosial Kepala Sekolah secara bersama-sama dengan pelaksanaan tugas guru BK dengan tingkat hubungan sebesar 0,618.

Berdasarkan hasil penelitian yang ditemukan ada beberapa sekolah yang belum memiliki fasilitas BK seperti ruang BK, sehingga pelayanan BK bersifat seadanya saja. Untuk mendapatkan dukungan sosial Kepala sekolah lebih lanjut dikemukakan oleh beberapa orang guru BK SMPN Kab. Kerinci agak sulit sehingga pelaksanaan BK kerap kali menemukan hambatan dalam melakukan pelayanan. Palayanan BK di sekolah belum mendapat anggaran yang jelas dari Kepala Sekolah, seperti untuk melakukan kunjungan rumah masih ada kepala sekolah yang keberatan memberikan dananya.

Hatch dan Steffire (dalam Achsan Husairi 2008:34) "Suatu program bimbingan yang baik membutuhkan sekitar $5 \%$ dari keseluruhan biaya pendidikan sekolah" tanpa adanya pembiayaan yang memadai, proses pelaksanaan program layanan bimbingan dan konseling cenderung akan mengalami hambatan. Efek Positif dari dukungan sosial yang diberikan oleh Kepala Sekolah kepada guru BK dalam menjalankan tugasnya dapat mempengaruhi tingkah laku guru BK karena merasa dibutuhkan, diperhatikan dan dihargai oleh Kepala Sekolah. Dengan demikian Pelaksanaan tugas guru BK di sekolah dapat berjalan dengan baik atas dukungan sosial Kepala Sekolah. Seperti yang dijelaskan oleh Cobb (dalam Smet 1994:136) Orientasi subjektif yang memperlihatkan bahwa dukungan sosial itu terdiri atas informasi yang menuntun orang menyakini bahwa ia diurus dan disayangi.

\section{Kesimpulan}

Berdasarkan hasil penelitian yang telah dilakukan dapat disimpulkan beberapa hal sebagai berikut:

1. Terdapat hubungan yang signifikan antara motivasi kerja dengan pelaksanaan tugas guru BK sebesar 0,781 artinya, semakin tinggi motivasi kerja maka pelaksanaan tugas guru BK akan semakin baik

2. Terdapat hubungan yang tidak signifikan antara dukungan sosial Kepala Sekolah dengan pelaksanaan tugas guru BK sebesar 0,145 artinya, tanpa adanya dukungan sosial Kepala Sekolah, pelaksanaan tugas guru BK akan mengalami hambatan di sekolah, pelayanan BK yang optimal sulit untuk diwujudkan.

3. Terdapat hubungan yang signifikan antara motivasi kerja dan dukungan sosial Kepala Sekolah secara bersama-sama dengan pelaksanaan tugas guru BK sebesar 0,618 artinya, adanya keterpaduan antara motivasi kerja dan dukungan sosial Kepala Sekolah secara bersama-sama dengan pelaksanaan tugas kerja 
Rahmawati, Neviyarni, Firman

(Hubungan Motivasi Kerja Dan Dukungan Sosial Kepala

Sekolah Dengan Pelaksanaan Tugas Guru Bk

Di Smpn Kab. Kerinci)

\section{DAFTAR RUJUKAN}

Achsan Husairi. (2008). Manajemen Pelayanan Bimbingan \& Konseling di Sekolah. Bogor. Arya Duta.

Robert. A. Baron dan Donn Byrne. (2003). Psikologi Sosial (Alih Bahasa Ratna Djuwita). Jakarta: Erlangga.

Dewa Ketut Sukardi. (2003). Manajemen Bimbingan dan Konseling di Sekolah. Bandung: Alfa Beta.

Hamzah B. Uno. (2010). Teori Motivasi dan Pengukurannya Analisis di Bidang Pendidikan. Jakarta: Bumi Aksara.

Hasibuan, SP. (2005). Organisasi \& Motivasi Dasar Peningkatan Produktifitas. Jakarta: BumiAksara.

Peraturan Pemerintah, Nomor 74 Tahun 2008 Tentang Guru. Jakarta: Depdiknas.

Smet, Bart. (1999). Psikologi Kesehatan. Jakarta: Grasindo.

Taylor, S. E. Peplau, L. A., Sears, D. O. (2003). Psikologi Sosial. New Jersey: Prentice Hall. 